\title{
Waist-To-Height Ratio as an Indicator of High Blood Pressure in Semi-Urban Indian School Children: A Cross-Sectional Study
}

Dr. Sunanda Jha ${ }^{1}$, Dr. Shyamanand Singh ${ }^{2}$, Dr. Umashanker Prasad Keshri ${ }^{3 *}$

${ }^{1}$ Associate Professor, Department of Paediatrics, Rajendra Institute of Medical Sciences (RIMS), Rims Cir, Indraprasth Colony, Bariatu, Ranchi, Jharkhand 834009, India

${ }^{2}$ Jr. Academic, Department of Paediatrics, Rajendra Institute of Medical Sciences (RIMS), Rims Cir, Indraprasth Colony, Bariatu, Ranchi, Jharkhand 834009 , India

${ }^{3}$ Professor, Department of Pharmacology, Rajendra Institute of Medical Sciences (RIMS), Rims Cir, Indraprasth Colony, Bariatu, Ranchi, Jharkhand 834009 , India

*Corresponding author: Dr. Umashanker Prasad Keshri

\section{Abstract}

The purpose of this study is to screen school going children of age 5 years to 16 years for hypertension by using waist to height ratio in Jharkhand. This study includes 640 healthy children after age group between 5 years to 16 years with no past history of any significant chronic illnesses. Anthropometric parameter is height and waist circumference and is measured in centimetres. Systolic \& Diastolic blood pressure has been measured in $\mathrm{mm}$ of $\mathrm{Hg}$ by sphygmomanometer in sitting position. Waist to height ratio was calculated as waist circumference $(\mathrm{cm}) /$ height $(\mathrm{cm})$. Children with a WHtR $<0.5$ were defined as normal whereas a WHtR more than or equal to 0.5 was defined as high WHtR. In our study we have selected 640 healthy children between the age group 5 yrs to 16 yrs out of which $70.46 \%$ were male and $29.53 \%$ were female children. In this 640 children $5 \%(n=32)$ were found to have high waist-to-height ratio. The proportion of children with high SBP and high DBP were $6 \%$ and $1 \%$ respectively out of 640 children. Within the high WHtR children $37 \%$ (12 children) have high SBP and 6\% (2 children) have high DBP. The ability to detect high systolic blood pressure or high diastolic blood pressure by waist-to-height ratio as a screening tool is statistically significant $(\mathrm{P}<0.001)$. Waist-to-height ratio has low sensitivity and thus some children may be missed by this method. Since it is very easy to measure and application of a single cut-point across all ages it may be a screening tool in Indian population and can be used widely during routine school physical examination.

Keywords: Hypertension, Waist Height ratio, physical examination.

Copyright @ 2020: This is an open-access article distributed under the terms of the Creative Commons Attribution license which permits unrestricted use, distribution, and reproduction in any medium for non-commercial use (NonCommercial, or CC-BY-NC) provided the original author and source are credited

\section{INTRODUCTION}

The waist-to -height ratio is a measure of the distribution of body fat. Higher values of waist-to-height ratio indicate a higher risk of obesity related cardiovascular diseases. Obesity and hypertension have both been on the rise in children. Each is associated with increased cardiovascular disease risk and both track into adulthood, increasing the prevalence of heart disease and related morbidity and mortality. There is an increase in incidence of high blood pressure in children these days. Various studies show that Indian children are more susceptible to obesity mediated hypertension. In pediatric age group blood pressure measurement and its interpretation requires skill which is difficult in school settings. Therefore use of anthropometric parameters which is a routine part of school physical examination can be used as an useful screening tool to identify children at high risk of developing hypertension. In various studies waist-to-height ratio, body mass index (BMI) and waist circumference is used as an obesity indicator. In this study we use waist-to- height ratio which is easy and suitable screening tool for obesity [1].

In various studies it has been found that children with obesity or severe obesity had higher blood pressure at baseline and a greater odd of developing hypertension years later than those who are not obese [2].

Adiposity is associated with elevated BP and hypertension through various pathophysiological pathways. Out of which most important is dysfunctional adipocyte and neurohormonal activation of the sympathetic nervous system (SNS). Adipocytes are storage depot of fat and an active endocrinological cell. In obese state there is an increase in adipocytes with an increase amount of adipokine synthesis. Adipokines 
Sunanda Jha et al., Sch Acad J Biosci, June., 2020; 8(6): 165-167

leads to an increase in SNS activity. Sympathetic nervous system activation can impact all organs but in obesity appears to preferentially impact the renal vascular beds. Obesity is associated with increased amounts of noradrenaline spill out from the kidneys thus increase in blood pressure. Also with increased activity of SNS, there is increase in renin-angiotensin-aldosterone-system (RAAS) activity. RAAS activity increases blood pressure directly (vasoconstriction) and indirectly (salt and water tubular reabsorption and $\mathrm{ADH}$ mediated water retention). Therefore the purpose of this study is to screen school going children of age between 5yrs to $16 \mathrm{yrs}$ for hypertension by using waist-to-height ratio in Jharkhand [3].

\section{MATERIAL AND METHODS}

This is a cross-sectional study done in 640 children of age between 5yrs to 16yrs (male $70.46 \%$ and female $29.53 \%$ ) in semi-urban school near Ranchi, Jharkhand. This study has been carried out in a private school in semi-urban region near Ranchi and written permission was taken from the school authority. Our study includes healthy children of the age group between $5 y r s$ to 16 yrs with no prior history of any significant chronic illness/illnesses. Written informed consent was taken from the parent/guardian of the selected children.

This study includes:

- Anthropometric parameters: height and waist circumference in centimeter.

- Systolic and Diastolic blood pressure in $\mathrm{mm}$ of $\mathrm{Hg}$.

- Height was measured by using a portable stadiometer.

- Waist circumference was taken by using a non-stretchable tape in standing position during expiration, at midpoint between lowest rib-cage and iliac crest.

Waist-to-height ratio was calculated as:

- Waist circumference $(\mathrm{cm}) /$ height $(\mathrm{cm})$.

- Blood pressure was measured by using mercury sphygmomanometer in sitting position and two readings were taken for all children.

- Average of two consecutive readings of blood pressure was taken for analysis.

\section{STATISTICAL ANALYSIS}

All children with BP more than or equal to $90^{\text {th }}$ percentile for SBP and more than or equal to $90^{\text {th }}$ percentile for DBP were classified as high SBP or high DBP. Children with a WHtR $<0.5$ were defined as normal whereas a WHtR more than or equal to 0.5 was defined as high WHtR. Two sided P-values $<0.05$ were considered statistically significant. Statistical analyses were performed using SPSS (IBM SPSS Statistics for Windows, Version 21.0.Armonk)

\section{RESULTS}

In this study 640 healthy children were selected between the age group 5yrs to $16 \mathrm{yrs}$ out of which $70.46 \%$ were male and $29.53 \%$ were female children. In this 640 children $5 \%(n=32)$ were found to have high waist-to-height ratio. The proportion of children with high SBP and high DBP were $6 \%$ and $1 \%$ respectively out of 640 children. Within the high WHtR children $37 \%$ (12 children) have high SBP and 6\% (2 children) have high DBP. The ability to detect high systolic blood pressure or high diastolic blood pressure by waist-to-height ratio as a screening tool is statistically significant $(\mathrm{P}<0.001)$.

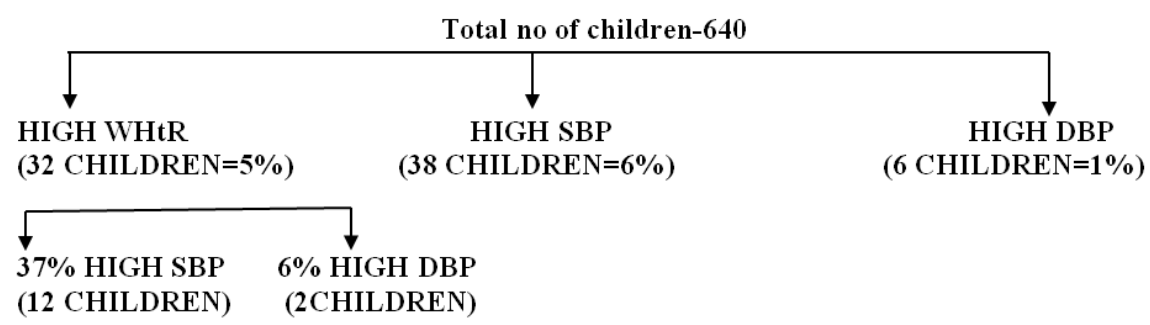

\section{DISCUSSION}

This study shows that there is a relation between increased waist-to-height ratio with increase in systolic and diastolic blood pressure. It's important to detect high blood pressure in pediatric age group as these children should be tracked as they have a possibility for adult hypertension. Blood pressure measurement in pediatric age group is difficult requires trained personnel, appropriate cuff size of sphygmomanometer and must be taken in quiet surroundings with a calm child. Thus routine school blood pressure screening by sphygmomanometer is laborious. Thus there is a requirement for a simple screening tool to identify children with high blood pressure. Simple screening tool includes [4]:

1. Waist-to-height ratio.

2. Waist circumference.

3. Body mass index (BMI).

As they serve as an alternate to blood pressure measurement and requires only simple anthropometric measurements. 
In this study waist-to-height ratio has been taken as a screening tool for increased blood pressure as it can be interpreted by well trained staff with no medical background. However as waist-to-height ratio is just a screening tool, children with WHtR $>0.5$ must be referred to a physician for confirmation and final diagnosis of high blood pressure.

Some limitations of ours study were:

1. Readings were taken on the same day.

2. No follow-up was done to confirm hypertension.

3. Study was done in semi-urban children only, required to be done in a more diverse population representing generalized population of children in India.

4. Waist-to-height ratio has low sensitivity and thus some children may be missed by this method.

5. Since it is very easy to measure and application of a single cut-point across all ages, we suggest it as a simple screening tool in Indian population and can be used widely during routine school physical examination.

6. Children with>0.5 WHtR should be screened with more sensitive screening tool to rule out hypertension and appropriate steps to be taken.

7. Waist-to-height ratio has low sensitivity and thus some children may be missed by this method.

Children with $>0.5$ WHtR should be screened with more sensitive screening tool to rule out hypertension and appropriate steps to be taken

\section{CONCLUSION}

Waist-to-height ratio has low sensitivity and thus some children may be missed by this method. Since it is very easy to measure and application of a single cut-point across all ages, we suggest it as a simple screening tool in Indian population and can be used widely during routine school physical examination.

\section{REFERENCES}

1. Brambilla P, Bedogni G, Heo M, Pietrobelli A. Waist circumference-to-height ratio predicts adiposity better than body mass index in children and adolescents. International journal of obesity. 2013 Jul;37(7):943-6.

2. Genovesi S, Antolini L, Gallieni M, Aiello A, Mandal SK, Doneda A, Giussani M, Stella A, Tucci B, Valsecchi MG. High prevalence of hypertension in normal and underweight Indian children. Journal of hypertension. 2011 Feb 1;29(2):217-21.

3. Raj M, Sundaram R, Paul M, Kumar K. Blood pressure distribution in Indian children. Indian Pediatr. 2010; 47:477-85.

4. McCarthy HD, Ashwell M. A study of central fatness using waist-to-height ratios in UK children and adolescents over two decades supports the simple message-'keep your waist circumference to less than half your height'. International journal of obesity. 2006 Jun;30(6):988-92. 